\title{
EM DEFESA DA FILOSOFIA: ENTRE UMA POSIÇÃO POLÍTICA E UMA FILOSOFIA EM SALA DE AULA
}

\section{IN DEFENSE OF PHILOSOPHY: BETWEEN A POLITICAL POSITION AND PHILOSOPHY IN THE CLASSROOM}

\author{
Rodrigo Pelloso Gelamo ${ }^{1}$ \\ Augusto Rodrigues ${ }^{2}$
}

Recebido: 08/2019

Aprovado: 11/2019

\begin{abstract}
Resumo: No contexto brasileiro, o lugar da filosofia na formação humana passa por uma constante desvalorização. Uma década após seu retorno como disciplina obrigatória do currículo da educação básica, já não há uma preocupação em defender sua presença como um saber disciplinar. Os acontecimentos do presente fazem com que emerja todo um discurso já construído no Brasil desde a década de 1980, em que a disciplina era pensada como crucial à formação humana, em razão das qualidades peculiares à tradição filosófica, de crítica e de resistência às imposições do tempo presente. Embora se reconheça a importância desse posicionamento político, o objetivo deste texto é problematizar a construção apenas abstrata de uma defesa da filosofia em sala de aula, sem que se pense nos limites e possibilidades das práticas de ensinar e aprender que atravessam a formação do professor de filosofia e a disciplina na educação básica. Assim, defendese que o engajamento político, em prol da presença da filosofia, só pode acontecer fundamentado em uma investigação sobre as relações que são estabelecidas, dentro da sala de aula, em nome da filosofia, de seu ensino e aprendizagem.
\end{abstract}

Palavras-chave: Ensino de filosofia; filosofia no Brasil; ensino médio; formação em filosofia.

\begin{abstract}
In the Brazilian context, the place of philosophy in human education has gone through constant devaluation. A decade after its return as a mandatory school subject of basic education curriculum, there is no longer a concern in defending its presence as a disciplinary knowledge. The events of the present time have caused the emergence of a discourse already constructed in Brazil since the 1980s, in which the subject used to be thought as crucial to human education. This was due the peculiar qualities to the philosophical tradition, of criticism and resistance to the impositions of the present time. Although the importance of this political position is acknowledged, the goal of this paper is to problematize the only abstract construction of defending philosophy in the classroom, without thinking about the limits and possibilities of teaching and learning practices that cross the philosophy teacher's education as well as the subject in basic education. Thus, it is argued that political engagement, in favor of the presence of philosophy, can only happen grounded on an investigation of the relationships that are established within the classroom, on behalf of philosophy as well as its teaching and learning.
\end{abstract}

Keywords: Philosophy teaching; philosophy in Brazil; High school; philosophy education..

\footnotetext{
${ }^{1}$ Programa de Pós-Graduação em Educação e Filosofia UNESP.

${ }^{2}$ Mestre em Educação pelo Programa de Pós-Graduação em Educação UNESP/Marília e Professor de Filosofia na Rede Estadual de São Paulo.
} 


\begin{abstract}
“Se a juventude é vista pelos acomodados como um 'incômodo', o mesmo acontece com a filosofia. No século V a.C., Sócrates, já idoso, foi condenado à morte pelo tribunal popular de Atenas. Diziam que ele não acreditava nos deuses da cidade e corrompia a juventude; mas na verdade ele incomodava demais aqueles que se sentiam confortáveis com a situação" (GALLO, 1997, p. 11)
\end{abstract}

Como estratégia de resistência ao cenário brasileiro atual, em que a presença da filosofia sofre constantes ameaças e é, muitas vezes, desvalorizada na formação humana, fomos convidados a pensar sua defesa e reafirmação dentro das escolas e universidades. Para estar à altura de tal convocação, experimentamo-nos, na escrita a quatro mãos, de um pensamento que pretende expressar uma convivência entre dois professores e pesquisadores do ensino de filosofia, de forma a intercruzar nossas experiências docentes - seja na atuação no curso de licenciatura em filosofia, seja na atuação na educação básica - a fim de pensar a temática proposta. Resolvemos também convidar, ao nosso exercício, um terceiro interlocutor, Sócrates - personagem muito cara não só à tradição fillosófica, mas, de uma maneira geral, àqueles que desejam ensinar e aprender filosofia.

Não são raras as vezes que um professor de filosofia se depara com a figura socrática no início dos livros didáticos ou em propostas para ensinar e aprender filosofia. Sócrates parece ser um dos mais hábeis condutores, a figura mais emblemática, para conduzir à filosofia as almas daqueles que ainda com ela não tomaram contato. Sua presença encarna o roteiro do filósofo em busca da sabedoria, estruturando a atividade filosófica justamente na potência da ignorância e, por consequência, na não aceitação dos pressupostos e das práticas vigentes. "Só sei que nada sei”! Esse jargão, muitas vezes repetido pelo imaginário popular e também filosófico, mostra fundamentalmente a ascendência de uma postura que viria a ser revivida como prática crucial à atitude filosófica e, sobretudo, à sua fama de incômodo e resistência.

Acusado de corromper a juventude e não acatar deuses cultivados pelos atenienses (PLATÃO, 24b), Sócrates, condenado à morte, deixa sua vida como legado de subversão à posterioridade. Dentro de sua sabedoria demasiadamente humana (PLATÃO, 20e), vivifica um lugar de exterioridade às tradições e coloca a filosofia justamente em um não-lugar, uma atopia. Sócrates é resistência porque não tem lugar na pólis; sua prática não se confunde com - pelo contrário, incomoda - as figuras já consagradas na cidade, tal como o estadista, os poetas e os artesãos. Por essa razão diz Wolff: 
é perseguido por suas ideias [...] toda voz intransigente que se eleva para resistir às consciências satisfeitas ou denunciar os desatinos coletivos, e é Sócrates que se revive. (1982, p. 1-2).

Tal como o que move Sócrates a filosofar é uma insatisfação com a ordem dominante e, ao mesmo tempo, a missão de perturbar seus interlocutores, conduzindo-os ao questionamento da própria vida e à tomada de consciência de si mesmos e do mundo de que participam (PLATÃO, 36e), a filosofia será intensamente defendida, no decorrer dos séculos, como indispensável ao tempo presente. Ao comparar o incômodo gerado pela filosofia com o incômodo caracteristicamente atribuído aos jovens, Silvio Gallo (1997) quer aproximar os estudantes a essa tradição de pensamento que pode ser revivenciada pela postura socrática. Se os jovens estão mais do que acostumados a serem tachados por desagradáveis, principalmente na escola, onde sua potência de vida, seu processo de transformação e de movimento são vistos como desordem e indisciplina às normas e aos conjuntos de valores estabelecidos, talvez com a filosofia eles possam se sentir mais à vontade; justamente por encontrarem nela uma potencialização de seu inconformismo, uma alavanca que estimule a construção de suas próprias vidas e seus caminhos.

No Brasil, principalmente na década de 1980, essa condição subversiva da filosofia e do seu ensino foi bastante defendida nas produções teóricas do ensino de filosofia. É que, em 1971, a disciplina foi totalmente retirada do cenário escolar pelo golpe militar. Construía-se, em resposta ao acontecimento, um discurso que tomou defesa pela presença obrigatória da filosofia na educação básica, como uma ferramenta crítica e transformadora da vida dos estudantes, cujas práticas seriam imprescindíveis à vida democrática. O desafio era explicitar para a sociedade e para os responsáveis pela educação em particular, da importância da recolocação da disciplina de filosofia na escola e da urgência de isso se efetivar (GELAMO, 2009, p. 43).

Os primeiros resultados desse movimento já apareceriam em meados dos anos 1980, especificamente quando a disciplina foi incluída como optativa na grade curricular de alguns estados brasileiros. Anos mais tardes, mesmo sem uma definição de seu caráter disciplinar, os conhecimentos filosóficos tornaram-se obrigatórios na educação básica por meio da Lei de Diretrizes e Bases da Educação Nacional de 1996. Com as conquistas legais prévias, seguidas pela aprovação do Congresso Nacional e do respectivo veto do presidente da República em 2001 do projeto de Lei n.3178/97³, que promulgava a obrigatoriedade da

\footnotetext{
${ }^{3}$ Nesse projeto de lei do Deputado Padre Roque (PT-PR), defendia-se a filosofia como disciplina obrigatória,
} 
disciplina na grade curricular, o debate se intensificava no cenário nacional, e a defesa incondicional da filosofia, de seu papel crítico e subversivo, adquiria mais força na luta pela ampliação de seu espaço institucional. Só depois de muita luta, a filosofia retornaria como disciplina obrigatória do currículo da educação básica no ano de $2008^{4}$. De fato, marcava-se uma vitória para o movimento que se iniciava nos anos de 1980 e, pouco a pouco, se solidificou no território nacional.

Entretanto, quase uma década após seu retorno como disciplina, a filosofia na formação básica dos brasileiros ocupa um lugar incerto. A BNCC (Base Nacional Comum Curricular) e a lei n. 13.415, de fevereiro de 2017, repetem o roteiro já usual de instabilidade do ensino de filosofia no contexto nacional (ALVES, 2002), de modo a recolocar a filosofia em um lugar duvidoso. Todo aquele discurso em torno da importância social da filosofia na formação crítica e subversiva do cidadão começa a pulsar novamente nos corredores das universidades, nas escolas e nas discussões da filosofia e seu ensino. A bandeira geral parece ser única: a filosofia precisa viver na escola, principalmente no cenário atual, para que haja ainda resistência aos tempos que se anunciam.

Mais do que necessário reviver e retomar o debate já instaurado em defesa da filosofia na educação, é preciso também resgatar uma parcela daquele movimento que ficou, muitas vezes, ofuscada em meio aos discursos apologéticos. Por um lado, do ponto de vista histórico, criava-se uma tendência associativa entre a retirada da filosofia do ensino médio à ordem política e ideológica, intensificando um discurso que prevê a necessidade da filosofia como uma disciplina que fornecerá uma formação crítica. Por outro, muito pouco se debateu em torno das práticas que permeariam o retorno da filosofia à escola, de modo a problematizar se o trabalho filosófico, que viria ser desenvolvido em sala de aula, ou que já ocorria parcialmente, tinha possibilidade de contribuir subversivamente ou não para a formação do educando.

Essa problemática Sofiste já anunciava no final da década de 1990. Antes mesmo do

não apenas como conhecimentos necessários e temas transversais. Para ele, a obrigatoriedade da disciplina se justificava porque somente os professores de filosofia seriam os maiores capacitados a fazerem funcionar uma disciplina que forneça uma formação integral dos estudantes, especialmente na sua compreensão crítica da relação homem-mundo. A princípio, o projeto é aprovado pela Câmara dos Deputados, sob a justificativa de uma luta histórica interrompida pelo período militar: momento em que a filosofia havia sido excluída do cenário educacional com a intenção de suprimir as liberdades democráticas, impedir o desenvolvimento de uma consciência crítica e reflexiva e garantir a obediência passiva do cidadão ao novo regime. Esse projeto de lei receberia o veto do então presidente Fernando Henrique Cardoso.

${ }^{4}$ BRASIL. Lei Federal no 11.684, de 02 de junho de 2008. Altera o art. 36 da Lei no 9.394, de 20 de dezembro de 1996, que estabelece as diretrizes e bases da educação nacional, para incluir a Filosofia e a Sociologia como disciplinas obrigatórias nos currículos do ensino médio. 
retorno obrigatório da filosofia ao currículo, o autor problematizava as imagens de superdisciplina construídas pelos seus defensores, cujas propostas se situavam fora da realidade, tornando-se não suficientes para pensar as próprias possibilidades da filosofia na escola. É como se bastasse apenas a inclusão dessa disciplina no ensino médio para que os estudantes se tornassem mais críticos e reflexivos, numa relação de causalidade direta. Todavia, o autor levanta o seguinte questionamento, tensionando a imprecisão das diferentes propostas que emergiam: "o que esperar de uma disciplina da qual não podemos dizer ao certo o que é, a que visa e a quem serve?" (SOFISTE, 1998, p. 110).

Nos anos 2000, Gallo e Kohan caminham nessa direção investigativa. Construíam uma tentativa de reflexão da filosofia sobre si mesma, problematizando as práticas de ensinar e aprender que se apresentavam comumente para pensar a presença da filosofia na educação básica. Nesse sentido, ofereciam ao debate uma crítica de alguns sentidos óbvios que sustentam as propostas de ensino, de modo a destacar as formas dominantes e os pressupostos que as organizam (GALLO; KOHAN, 2001). Para eles, qualquer pretensão de levar a filosofia à sala de aula passava pela necessidade de se pensar previamente sobre o "quê" e o "para quê" de sua prática educacional. Por essa razão, a defesa da filosofia nos espaços institucionais, precisava estar ancorada em um questionamento que problematizasse a relação que professores e estudantes estabelecem com a filosofia nesses lugares, os pressupostos que perpassam suas práticas, sua finalidade na escola, etc.. Afinal, o que se ensina e se aprende sob o nome de filosofia? Isto é, sob a chancela de uma disciplina intrinsicamente crítica e subversiva, cuja qualidade se torna imprescindível à formação e intervenção resistente na realidade?

Basicamente, são esses tensionamentos que Kohan retoma em sua participação no I Simpósio Sul-Brasileiro Sobre o Ensino de Filosofia e o III Encontro dos Cursos de Filosofia do Sul do Brasil em 2001. De fato, desde a retirada da filosofia das escolas, muito se havia conquistado no cenário nacional. A presença da filosofia permanecia mais viva nas manifestações sociais, seja ao habitar parcialmente os lugares institucionais de educação, seja ao ocupar espaços não-institucionais, ao exemplo das práticas de cafés filosóficos e debates interdisciplinares na mídia. Se esse contexto trazia otimismo e fortalecia o movimento, algumas questões ainda permaneciam em aberto, principalmente no que diz respeito às práticas desenvolvidas nesses espaços sob o nome de filosofia: 
na cultura brasileira daquela que ocupava há algumas décadas atrás, inviabilizadas no ensino superior, reclusa a umas poucas escolas, impraticável no espaço público da cidade. Com base nessa conjuntura, muitas amantes sorriem. Fala-se até de "febre" pela filosofia, de "explosão" da filosofia no Brasil. Sou algo mais cauto. Não considero interessante apenas que a filosofia ocupe espaços. Dentro e fora das escolas, importa, fundamentalmente, compreender o que ela faz nesses espaços, o tipo de filosofia que se pratica (e ensina), sua relação com outras áreas do saber, com a instituição escolar e as outras instituições da vida econômica, social e política do país. Convém, especialmente, considerar a relação que professores e alunos envolvidos com a filosofia estabelecem entre si e com ela. Importa, antes de mais nada, o tipo de pensamento que se afirma e se promove sob o nome de filosofia (KOHAN, 2002, p. 22)

Essas críticas à qualidade de pensamento produzida com a presença da filosofia, seja na mídia, seja na escola e nas relações que os professores e alunos envolvidos estabelecem entre si e na disciplina, são relevantes a fim de que nos posicionemos em defesa da filosofia na contemporaneidade. Isso porque, apesar de sua presença, aquilo que se evidenciou não foi uma apropriação cultural da filosofia na vida social, tanto no pensamento quanto nas atitudes das pessoas. De fato, não basta simplesmente que a filosofia ocupe espaços no cenário nacional. Seria fundamental indagar e problematizar que práticas se estabelecem nos espaços que, pouco a pouco, havíamos adquirido o direito de ocupar. Ora, sob o nome de qual filosofia e práticas defendemos a presença da filosofia no Brasil?

Certamente esse tensionamento não ecoou muito no movimento e no debate que precedia o retorno da disciplina na educação básica - nem mesmo na produção pós-retorno institucional da filosofia. De acordo com as nossas pesquisas, a hegemonia do debate sobre o ensino de filosofia no Brasil circulou, e ainda circula, fundamentalmente em torno de três questões: (1) sobre o entendimento da importância do ensino da filosofia para a sociedade, para a cultura, e para a formação crítica do homem; (2) a reflexão sobre os temas e conteúdos a serem ensinados e sobre o currículo; (3) a busca do entendimento metodológico do ensino da filosofia (GELAMO, 2009, p. 35). Sendo que a maior concentração de produção se encontra na discussão das questões político-educacionais concernentes à importância da filosofia e do seu ensino na formação humana.

Quando o ensino de filosofia se concentra em torno dessas três questões, intensificase, em parte, um modo de olhar que se preocupa apenas com as condições educacionais e pedagógicas da filosofia. Nesse sentido, a discussão se dedicou a debater métodos que possam operar os conteúdos e uma didática da filosofia. Por outro lado, ao insistir no caráter estritamente pedagógico da questão do ensino de filosofia, perpetua-se, hegemonicamente, 
uma defesa incondicional da disciplina na escola, em outros cursos universitários e fora dos muros institucionais. O problema é que essa forma de debater a temática permanece presa às representações abstratas da filosofia e de seu funcionamento dentro de um ideal também abstrato de formação, que não dão conta de dar densidade filosófica às relações estabelecidas nos espaços que a filosofia voltava a ocupar.

Na direção desse diagnóstico, temos a pesquisa de Elisete Tomazetti. Ao investigar a produção discursiva em torno do ensino e aprendizagem filosófica no Simpósio Sul-Brasileiro sobre o Ensino de Filosofia (2001-2010) - um dos principais eventos que reuniu a participação de pesquisadores e professores para se discutir o ensino da disciplina -, a pesquisadora problematiza justamente a imprecisão da principal bandeira do movimento de defesa do retorno da filosofia à escola: o ensino de filosofia como ensinar e aprender a filosofar. De acordo com suas observações, não existiu uma unidade de debate e tampouco de sentido nessas afirmações, prevalecendo uma defesa abstrata da disciplina como lugar de promoção do filosofar. Por consequência, a defesa de um filosofar nas instituições educacionais recaía em lugares genéricos e abstratos - que poderiam ser muito bem defendidos por outras disciplinas -, tal como a defesa do espírito crítico e criativo da filosofia na formação humana:

Pensar criticamente, exercitar o pensamento crítico, são funções do ensino de Filosofia frequentemente apontadas. [...] A função da disciplina seria, então, transformar os estudantes, que por sua vez, transformariam a realidade, o seu mundo. No entanto, constata-se, em muitos discursos, que se trata de uma determinação genérica, que poderia ser manifestada, sem nenhum impedimento, como objetivo de outras disciplinas escolares. Nesse caso, pela análise realizada, percebemos uma carência de argumentos que pudessem evidenciar a especificidade do ensino do filosofar e do ensino do pensamento crítico no contexto das escolas contemporâneas (TOMAZETTI, 2011, p. 91-92).

Nesse sentido, sem a construção de um discurso que problematize a especificidade do filosofar e do ensino de filosofia nas escolas contemporâneas, que pense as relações que professores e alunos estabelecem com a filosofia, inúmeras dificuldades permanecerão na construção e defesa de seu espaço institucional. Por essa razão, para estarmos à altura dos acontecimentos que envolvem o ensino de filosofia na contemporaneidade, necessitamos pensar por outro registro: fazer uma filosofia do ensino de filosofia, repetindo não só as tentativas mais recentes como as de Sofiste, Kohan, Gallo e Tomazetti, mas de toda uma tradição que se debruça filosoficamente nas questões que perpassam a filosofia e seu ensino. 
E um dos caminhos possíveis a esse projeto filosófico é repensar as próprias práticas que já estabelecemos com a filosofia na atualidade.

Embora a filosofia ocupe, nesse exato momento, um espaço incerto dentro do currículo básico brasileiro, tivemos quase uma década de obrigatoriedade do ensino de filosofia. Por conseguinte, como desconsiderar as heranças que sustentam esse ensino e a aprendizagem, seja através da formação do professor, que exercita e estabelece uma relação com a filosofia e com seus estudantes, seja nas próprias diretrizes oficiais que organizam a disciplina? Como defender a filosofia e um filosofar em sala de aula sem que problematizemos as práticas que já atravessam a realidade escolar e a modelam na formação dos professores de filosofia? Assim, não obstante reconhecermos a importância do debate, que circula nas produções sobre o ensino de filosofia no Brasil, que ainda é primordial na defesa pública da filosofia, não poderíamos deixar de pensar filosoficamente as próprias especificidades que construímos com ela e suas condições no tempo presente.

Se olharmos especificamente para o lugar em que as práticas da filosofia se produzem, ou seja, dentro das salas de aulas, das universidades e das escolas ${ }^{5}$, é perceptível que tanto a disciplina no ensino médio quanto a formação de seu professor estão organizadas em torno de uma herança, cujas práticas de ensinar e aprender estão bem demarcadas historicamente no contexto brasileiro. Desde que o futuro professor de filosofia inicia seus primeiros passos na universidade, sua prática com a filosofia é modelada sob uma herança que tem como cerne de sua formação o ensino e aprendizagem da história da filosofia (RODRIGUES, 2019, p. 110). Em nosso contexto formativo, história da filosofia tem um significado específico: a leitura explicativa dos clássicos. Trata-se de uma constituição de ensinar e aprender cuja herança nos remonta ao curso de filosofia da Universidade de São Paulo (USP), mais especificamente a uma prática acadêmica consolidada na década de 1960, sob a tutela de uma convivência universitária com dois patronos, Martial Guéroult e Victor Goldschmidt:

[...] o conhecimento da história da filosofia entre nós, realçada por uma convivência universitária com quem melhor representava o padrão adotado, deu-se, pois, por meio da obra de Guéroult e Goldschmit, cujo aprendizado resulta uma formação filosófica, acadêmica e intelectual (MARQUES, 2007, p. 29).

\footnotetext{
${ }^{5}$ Com isso não afirmamos que todas as práticas de ensinar e aprender filosofia na realidade brasileira estão reduzidas a essa única herança a qual iremos explorar. Por um lado, reconhecemos sua influência principalmente no contexto do Estado de São Paulo, nas suas universidades estaduais e federais e na construção do Currículo oficial desse mesmo Estado. Por outro lado, essa herança também aparece nas diretrizes curriculares nacionais, como são os casos dos Parâmetros Curriculares Nacionais: Ensino Médio (2002) e Orientações Curriculares Ensino Médio (2006) (RODRIGUES, 2019).
} 
A geração de professores da década de 1960 da USP encontraria no método de análise estrutural os momentos mais altos da "metodologia científica em história da filosofia" (PEREIRA, 1970, p. 6) e, por consequência, o recurso propedêutico, acadêmico e intelectual, necessário à formação filosófica que se instalava nesta universidade. Isso porque o método estrutural sempre foi visto como uma etapa formativa primeira, um instrumento pedagógico essencial, cujo objetivo era a promoção de uma formação voltada ao senso crítico e histórico da filosofia, sob o crivo da especialização. Assim, antes de qualquer possibilidade de se refletir filosoficamente, se pressupôs necessária uma preparação técnica com a história da filosofia. O motivo que justificava era um suposto diagnóstico em torno de uma produção pseudo-filosófica, um estilo de pensamento supostamente sem critérios acadêmicos, que existia antes da criação do curso de Filosofia da USP (PRADO JR, 1988, p. 67).

Contava a favor da metodologia estruturalista do Departamento de Filosofia certo distanciamento interpretativo, que supostamente tangia de objetividade e rigor científico a explicação e transmissão das doutrinas filosóficas. Essa objetividade seria garantida por um exercício de explicação dos textos clássicos, sob uma prática de duplo isolamento: o texto em relação ao contexto da história do pensamento; e explicação do texto e sua possível conexão com os problemas que afloram da realidade social (GUIDO ET AL, 2013, p. 114-115). No primeiro caso, privilegia-se a leitura dos próprios textos porque são preponderantemente neles que se encontra a "lógica interna" dos sistemas filosóficos - única via possível para reconstituição das verdades formais de cada sistema, segundo as verdadeiras intenções do autor -, e não na história das ideias e nos acontecimentos que circunscrevem a obra filosófica no tempo. No segundo, a leitura filosófica opera sem estabelecer vínculos entre os clássicos e os problemas do presente, pois não são os valores materiais dos juízos que atribuem conotação filosófica à leitura dos sistemas, mas suas próprias constituições enquanto juízos da razão. Dessa forma, se mantém o trabalho na esfera apenas da interpretação e explicação dos sistemas filosóficos e suas verdades formais, enquanto expressão das diversas facetas dos sopros espirituais da razão (GOLDSCHMIDT, 1970 [1953]; GUÉROULT, 2007 [1957], 1968 [1956]).

Em nossa pesquisa, diagnosticamos que boa parte de nossa formação como professores gira em torno do desenvolvimento de um conhecimento técnico e explicativo da história da filosofia de proveniência uspiana. Sem preocupação com os problemas que nos afetam - até porque os problemas, dentro dessa tradição, "antes de tomarem corpo, costumam 
ser uma maneira de dissertar" (ARANTES, 1994, p. 27) -, trilhamos um trajeto como aprendizes de um vínculo substancial explicativo com a tradição filosófica. Sejam as disciplinas temáticas, sejam as tipicamente historiográficas, adquirimos uma bagagem de práticas explicativas com a filosofia que, por consequência, se manifestará no ensino de filosofia na educação básica (RODRIGUES, 2019, p. 109). Na realidade, essa é aposta do Projeto Pedagógico da universidade da qual fazemos parte. Nessa proposta, a formação do professor de filosofia passa pelo acúmulo da cultura filosófica de maneira rigorosa e científica da história da filosofia, sob a tutela da aquisição de uma precisa ferramenta: a técnica de "explicação de texto" - habilidade não só utilizada na elaboração de comentários originais específicos aos profissionais formados na área, como também crucial para mediar o acesso à história da filosofia. Espera-se, portanto, que, depois de quatro a cinco anos, o professor de filosofia saia "familiarizado com a técnica de explicação de texto", a qual a transforma também em "privilegiado instrumento do ensino de filosofia do $2^{\circ}$ grau" (UNESP, s/p, s/d).

Entretanto, qual é a potencialidade da técnica de explicação de texto, amparada no registro metodológico estruturalista, dentro das salas de aula da educação básica? Embora esse projeto pedagógico que começa no Departamento de Filosofia da USP e se manifesta em outros departamentos de filosofia, nos forneça bons trabalhos de tradução, de interpretações e a expansão de um senso histórico - que antes não existia no cenário nacional -, em contrapartida, como efeito colateral, cultiva-se uma relação passiva com os clássicos e com os problemas do tempo presente. Pela própria característica dessa herança, não nos habituamos a debater e criticar o que se lê, porque não são os juízos materiais que importam na leitura de um clássico, mas a sua estrutura lógica e arquitetônica. Não aprendemos a construir, por consequência, relações problemáticas entre a nossa vida e os clássicos, fundamentalmente em razão da neutralização do contexto e de suas nuances na explicação dos textos. Então, que tipo de exercícios podemos estabelecer com a filosofia na educação básica, se a maneira como nos modelamos na licenciatura é por meio de um vínculo técnico que, no máximo, nos fornece um conhecimento representacional sobre a história da filosofia? Teríamos nós, no ofício de professores, condições de formular filosoficamente questões éticas, políticas, científicas ou artísticas da atualidade? É isso o que diagnosticamos ao observar as ressonâncias dessa herança em sua prática de ensino e também na de outros professores:

Como não aprendemos a ser críticos na leitura explicativa da história da filosofia, não exercitamos na licenciatura a capacidade de crítica e de pensamento, nossas práticas de ensinar e aprender filosofia eram reduzidas à 
explicação e à compreensão da história da filosofia. Ora, não fomos estimulados a questionar o próprio conteúdo do que era explicado pelos nossos professores, afinal de contas, ler e explicar um texto filosófico não tem relação com as possibilidades matérias das doutrinas filosóficas. $\mathrm{Ou}$ seja, não vivenciamos em sala de aula práticas que estabeleciam um vínculo problemático com a história da filosofia e com os problemas filosóficos. (RODRIGUES, 2019, p. 113).

Por essa razão, desde o lugar do professor de filosofia, como poderemos defender a presença da filosofia na educação básica, sob uma imagem de crítica e resistência, se nossas heranças formativas não nos dão condições para construirmos com nossos estudantes em sala de aula vínculos dessa qualidade? De fato, o problema se amplia justamente porque essa herança não se manifesta apenas na formação do professor, mas invade as diretrizes da disciplina na escola. O retorno lento da filosofia, desde 1982, às escolas fez com que a disciplina sofresse pressão das universidades, que agora voltam-se seus olhares à realidade da educação básica e impõem para fazer da "história da filosofia a única didática da disciplina" possível (GUIDO ET AL, 2013, p. 114). Assim, fora o descompasso entre a nossa formação e a capacidade de fazermos jus à fama crítica e subversiva da filosofia dentro de nossas práticas de ensinar e aprender, há toda uma pressão institucional para que organizemos o currículo da disciplina na educação básica em torno dessa herança que não fornece bases para tanto.

Nesse sentido, sob a tutela dessa herança, muitas são as nossas dificuldades de fazer da sala de aula um lugar de crítica e resistência, como requer boa parte das lutas que defendem a presença da filosofia na escola e mesmo na universidade. Para que a filosofia permaneça viva na formação humana, seja na escola, nos espaços universitários e não institucionais, de forma a ocupar seu papel de exercício de resistência e incômodo que sempre lhe foi característico, precisamos ressignificar as nossas condições e os próprios vínculos que estabelecemos com a filosofia quando nos propomos a ensiná-la e aprendê-la. Em outras palavras, para defender uma prática filosófica nos espaços em que filosofia possa habitar no cenário brasileiro, é preciso repensar e problematizar essa herança e tradição universitária que invade a formação do professor e organiza também a disciplina no ensino médio. Para tanto, podemos novamente convocar Sócrates para a frente de batalha. Mas dessa vez a personalidade socrática não só nos servirá como ponto de tensão entre filosofia e a pólis, e sim, sobretudo, como resistência à própria filosofia, ou melhor, como ponto de inflexão sobre a nossas heranças de ensinar e aprender.

Também com Sócrates, a filosofia subverte sua própria tradição: resiste ao terreno das investigações físicas, às suas visões cósmicas, às questões tautológicas (o que é o ser? o que é 
o que é?), de maneira a retomar as operações abertas para pensar diferentemente seu próprio presente. Não são mais os mistérios da geração da matéria e da vida que o espanta, são as condutas humanas, mais precisamente a ausência de fundamentação do agir grego. Por essa razão, é sobre seu tempo que Sócrates deseja agir e é Atenas que deseja reformar, dirigindo-se a cada ateniense. Assim, se Sócrates recupera a operação investigativa dos filósofos présocráticos, a especulação que lhe é característica, é justamente para refazê-la e recolocá-la no terreno das preocupações vitais do cidadão ateniense, fundamentalmente dos costumes e comportamentos, isto é, dos “ethos” (WOLFF, 1978, p. 35).

Ora, é esse Sócrates que resistiu à própria filosofia, que funciona como exemplo de subversão à cidade, que transpira a inquietude característica à filosofia. E será justamente porque Sócrates ressignificou e subverteu a própria tradição filosófica que, em sua velhice, seria condenado por corromper a juventude - exemplo que inspira os diversos livros didáticos e situações de ensino e aprendizagem em filosofia. Por essa razão, não será preciso que nós também resistamos às tradições hegemônicas de ensinar e aprender filosofia no presente, a fim de que haja realmente possibilidades de se construir coletivamente uma prática de resistência com a filosofia? Talvez, só assim, possamos ainda defender a filosofia.

\section{Referências}

ALVES, Dalton José. A filosofia no ensino médio: ambiguidades e contradições na LDB. Campinas, SP: Autores Associados, 2002.

ARANTES, Paulo Eduardo. Um Departamento Francês de Ultramar: estudos sobre a formação da cultura filosófica uspiana. Rio de Janeiro: Paz e terra, 1994.

BRASIL. Congresso Nacional. Câmara dos Deputados. Padre Roque Zimmemann. Projeto de Lei 3178/1997. Altera dispositivos do art. 36. Da Lei n 9.394, de 20 de dezembro de 1996, que estabelece as diretrizes e bases da educação nacional - Brasília, DF, 1997.

BRASIL. Lei Federal $n^{\circ} 11.684$, de 02 de junho de 2008. Altera o art. 36 da Lei no 9.394, de 20 de dezembro de 1996, que estabelece as diretrizes e bases da educação nacional, para incluir a Filosofia e a Sociologia como disciplinas obrigatórias nos currículos do ensino médio.

BRASIL. Secretaria de Educação Básica. Orientações Curriculares de Filosofia (OCEM). Brasília: MEC/SEB, 2006.

BRASIL. Secretaria da Educação Média e Tecnológica. Parâmetros Curriculares Nacionais: ensino médio. Brasília: MEC/SEMTEC, 2002.

GALLO, Silvio (coord). Ética e Cidadania: Caminhos da filosofia: Elementos para o ensino de filosofia. 15a Ed. Campinas: Papirus, 2007. 
GELAMO, Rodrigo Pelloso. Ensino da filosofia no limiar da contemporaneidade: O que faz o filósofo quando o seu ofício é ser professor de filosofia? São Paulo: Cultura Acadêmica, 2009.

GUIDO, Humberto; GALLO, Sílvio; KOHAN, Walter Osmar. Princípios e possibilidades para uma metodologia filosófica do ensino de filosofia: história, temas, problemas. In:

CARVALHO, Marcelo; CORNELLI, Gabriele (Org). Ensinar Filosofia. Cuiabá: Central de Texto, 2013.

GOLDSCHMIDT, Victor. A Religião de Platão. Trad: Ieda e Oswaldo Porchat Pereira. $2^{\mathrm{a}}$ ed., São Paulo: Difusão Europeia do Livro, 1970 [1953].

GUÉROULT, Martial. Lógica, arquitetônica e estruturas constitutivas dos sistemas filosóficos. Trad. Pedro Jonas de Almeida. Trans/form/ação, São Paulo, v. 30, n. 1, p. 235 246, 2007 [1957].

O problema da legitimidade da história da filosofia. Revista de História, São Paulo, v. 37, n. 75, p. 189- 211, 1968 [1956].

KOHAN, Walter. Perspectivas atuais do ensino de Filosofia no Brasil. In: FÁVERO, Altair Alberto; RAUBER, Jaime José; KOHAN, Walter Omar (Org.). Um olhar sobre o ensino de Filosofia. Ijuí: Unijuí, 2002. p. 21- 40.

KOHAN, Walter Omar; GALLO, Sílvio. Crítica de alguns lugares comuns ao se pensar a filosofia no ensino médio. In: KOHAN, W. GALLO, S (orgs). Filosofia no ensino médio. Petrópolis: Vozes, 2001.

MARQUES, Ubirajara Rancan de Azevedo. A Escola Francesa de Historiografia da Filosofia: Notas Históricas e Elementos de Formação. São Paulo: Editor

PLATÃo. Êutifon, Apologia de Sócrates, Críton. 4. ed. Lisboa: Casa da Moeda, 1983. Tradução, Introdução e Notas de José Trindade Santos

PRADO JÚNIOR, Bento. As filosofias da Maria Antônia (1956-1959) na Memória de um Ex Aluno. Maria Antônia: uma rua na contramão. São Paulo: Nobel, p. 66-81, 1988.

RODRIGUES, Augusto. Como nos tornamos os professores que somos: uma problematização da herança estruturalista nas práticas de ensinar e aprender filosofia. Dissertação (Mestrado em Educação)- Faculdade de Filosofia e Ciências, Universidade Estadual Paulista. Marília, 2019.

SOFISTE, J. A filosofia para crianças e o ensino de filosofia: Ética e filosofia política, v. 3, n. 2. Juiz de Fora: UFJF, 1998.

TOMAZETTI, Elisete M.. Produção discursiva sobre ensino e aprendizagem filosófica. Educ. rev., Curitiba, n. 46, p. 83-98, Dez 2012 .

UNESP. Projeto Pedagógico do Curso de Filosofia da UNESP, Marília, s/d, s/p. Disponível em: http://www.marilia.unesp.br/Home/Graduacao/Filosofia/projeto.pdf. Acesso em: 15 mar. 2019.

WOLFF, Francis. Sócrates - o sorriso da razão. Tradução de Franklin Leopoldo e Silva. São Paulo, Brasiliense, 1987. 